Asian Pacific Journal of Reproduction

Journal homepage: www.apjr.net

doi: $10.12980 /$ apjr.6.20170103

@2017 by the Asian Pacific Journal of Reproduction. All rights reserved.

\title{
Effect of bovine pellucid zone 3 monoclonal antibodies on B cell lymphoma 2 expressions of granulosa cell and mice (Mus musculus) follicle diameter
}

\author{
Heti Ira Ayue ${ }^{1,2 \varpi}$, Sutrisno Sutrisno ${ }^{3}$, Sanarto Santoso ${ }^{4}$ \\ ${ }^{I}$ Diploma III Midwifery Programme, Health Polytechnical of Palangkaraya, Health Ministry, Central Kalimantan, Indonesia \\ ${ }^{2}$ Midwifery Master Study Programme, Faculty of Medicine, University of Brawijaya, Malang, East Java, Indonesia \\ ${ }^{3}$ Division of Fertility, Endocrinology, and Reproduction, Department of Obstetrics and Gynaecology, Saiful Anwar General Hospital, Faculty of \\ Medicine, University of Brawijaya, Malang, East Java, Indonesia \\ ${ }^{4}$ Microbiology Laboratory, Faculty of Medicine, University of Brawijaya, Malang, East Java, Indonesia
}

\section{ARTICLE INFO}

Article history:

Received 10 Dctober 2016

Revision 12 November 2016

Accepted 21 Decembre 2016

Available online 1 January 2017

Keywords:

bZP3 monoclonal antibodies

BCL-2

Follicle diameter
ABSTRACT

Objective: To evaluate the effects of pellucid zone 3 monoclonal antibodies against B-cell lymphoma 2 (BCL-2) expression and mice follicle diameter at various time periods. Methods: The animal model of this study was $36 \mathrm{Balb} / \mathrm{c}$ mice (Mus musculus). A true experimental design was used with a post-test only control group approach. BCL-2 expression was observed using immunohistochemistry, while the follicle diameter was observed by haematoxylin-eosin staining. The data was analyzed using nested ANOVA to compare the results of the mean expression of BCL-2 on the 5th and 20th day of observation in the pre-antral and antral follicle between the control and treatment groups. Results: No significant differences were found in BCL-2 gene expression. There were also no significant differences in BCL-2 expression on the 10th day of pre-antral follicle analysis. Moreover, there were no significant differences between the mean follicle diameter on the 5th, 10th, and 20th day of pre-antral and antral follicle development between the control and treatment groups. The addition of bovine pellucid zone 3 (bZP3) monoclonal antibodies on the 5th and 20th day of observation did not decrease the expression of BCL-2 gene in the pre-antral and antral follicle of mice. Administering bZP3 monoclonal antibodies on the 10th day of observation did not affect BCL-2 expression in the pre-antral follicle but did decrease BCL-2 expression in the antral follicle. Supplying bZP3 monoclonal antibodies on the 5th, 10th and 20th day did not affect the diameter of pre-antral and antral follicles of the mice. Conclusion: The monoclonal antibodies bovine zona pelusida 3 has the potential to be developed as a safe immunocontraception preparation.

\section{Introduction}

Although contraceptive methods are used to control population growth rates, conventional contraceptions in use today cause various side effects. Therefore, immunocontraception has been developed as a candidate for a safer and reversible approach. One of the immunocontraceptive candidates currently being developed is pellucid zone (ZP), which inhibits the interaction between sperm and ovum. The human ZP-specific glycoprotein molecule consists of ZP1, ZP2, ZP3, and ZP4. Among those components, ZP3 plays an

Corresponding author: Heti Ira Ayue, Diploma III Midwifery Programme, Health Polytechnical of Palangkaraya, Health Ministry, Central Kalimantan, Indonesia.

E-mail: hetiiraayue@poltekkes-palangkaraya.ac.id. important role as the primary receptor to identify the spermatozoa and stimulate the acrosome reaction[1-3].

Follicles are present in various sizes to represent the various folliculogenesis stages. The enlargement of follicle diameter is an important morphological aspect as the follicles enter the growth stage and result in granulosa cell proliferation, an increase in the size of oocytes and the beginning of theca formation. The size of the

This is an open access article distributed under the terms of the Creative Commons Attribution-Non Commercial-Share Alike 3.0 License, which allows others to remix, tweak and buid upon the work non-commercially, as long as the author is credited and the new creations are licensed under the identical terms.

For reprints contact: reprints@medknow.com

C2017 Asian Pacific Journal of Reproduction Produced by Wolters Kluwer- Medknow

How to cite this article: Heti Ira Ayue, Sutrisno Sutrisno, Sanarto Santoso. Effect of bovine pellucid zone 3 monoclonal antibodies on B cell lymphoma 2 expressions of granulosa cell and mice (Mus musculus) follicle diameter. Asian Pac J Reprod 2017; 6(1): 13-17. 
follicle diameter can be used to determine the follicle's viability[4-6].

The ZP antibodies are proposed to affect the function of ovarium granulosa cells[7]. Granulosa cells are a location where B cell lymphoma 2 (BCL-2) is expressed, which is very important to maintain the cell's viability[8]. There is an discussed thoroughly issue about the potential of immunocontraception, hence the research on the potential of immunocontraception with glycoprotein ZP and $\mathrm{ZP}$ antibodies is still being conducted to assess its effectiveness in preventing fertilization and its impact on ovarian function[3].

\section{Materials and methods}

A true experimental design was followed with a post-test only control group approach that was conducted in the Parasitology Laboratory of the Medical Faculty of Brawijaya University and in the Veterinary Pathological Laboratory of the Veterinary Faculty of Airlangga University. The samples included 36 female mice (Mus musculus) (6 wk old, average weight 20-21 g) that were divided into six groups (6 each). Three control groups (group 1, 2 and 3) were administered $50 \mu \mathrm{L}$ of PBS and three treatment groups (group 4 , 5 and 6) were administered $50 \mu \mathrm{L}$ of monoclonal antibodies bovine zona pelusida 3 (Mab bZP3). The mice were dissected on day 5 (for group 1 and 4), day 10 (group 2 and 5) and on day 20 (group 3 and 6). BCL-2 expression was analyzed by immunohistochemistry and follicle diameters were observed by hematoxylin and eosin staining. The resultant data was analyzed by nested ANOVA and least significant difference (LSD) $5 \%$.

Mab bZP3, an immuno-contraceptive material, which was donated by Prof. Dr. drh Aulanni' am, Professor of Biochemistry, Brawijaya University. Mab bZP3 uses the basic substance of oocyte pellucid zone (bovine), made with hybridoma technique to produce Mab bZP3 in $\mathrm{AI}(\mathrm{OH})_{3}$ (Aluna Hydrogel) as adjuvant.

\subsection{The treatment allocation}

Prior to the treatment, acclimatization was conducted for $10 \mathrm{~d}$ so that the mice could adapt to the new environment. Next, a vaginal swab was performed to determine whether the mice were in the estrous phase. Mice in estrous were directly treated by intramuscular (im) injection of $50 \mu \mathrm{L}$ of PBS in control groups (group 1, 2 and 3) and $50 \mu \mathrm{L}$ Mab bZP3 in the treatment groups (group 4, 5, 6).

\subsection{Immunohistochemistry and hematoxylin and eosin staining}

Mouse ovaries were dissected and histologically prepared for immunohistochemistry and hematoxylin and eosin staining (Figure 1, 2). Dissection was conducted on day 5 (for group 1 and 4), on day 10 (for group 2 and 5) and on day 20 (for group 3 and 6). The left and right ovaries were removed from the mice by surgery and fixed in a $10 \%$ PFA solution for histopathological analysis and for immunohistochemistry and hematoxylin and eosin staining.

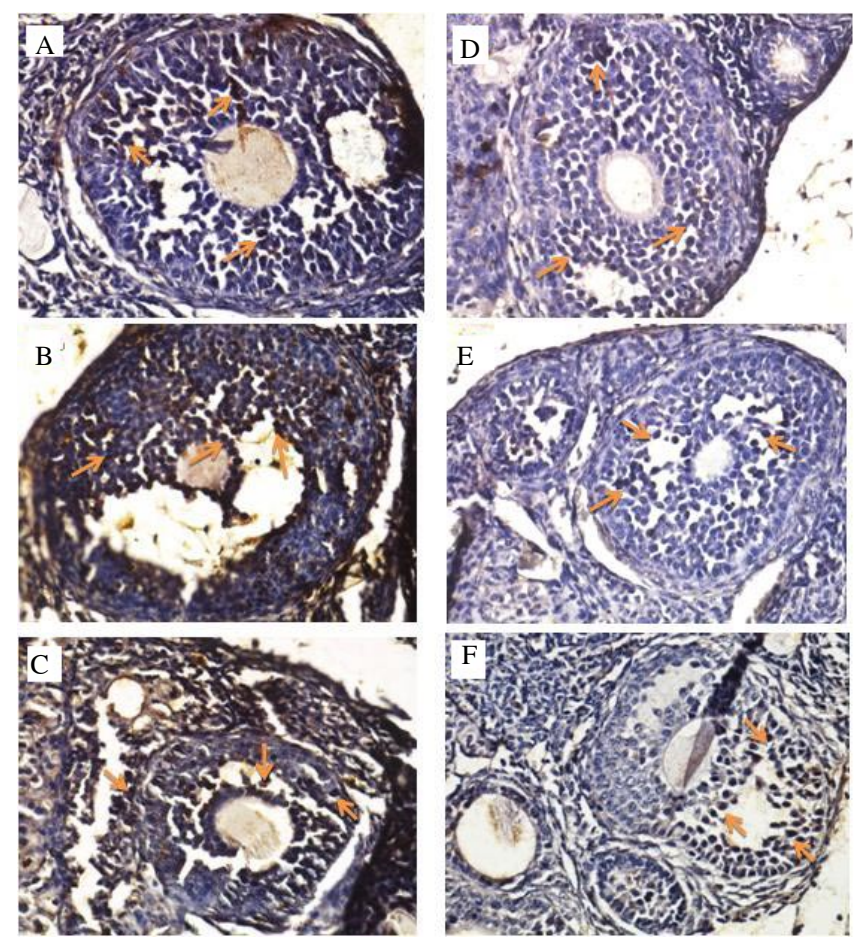

Figure 1. Comparison of BCL-2 expression in antral follicle granulosa cells. Note: A (group 1), B (group 2), C (group 3) are control groups exposed to 50 $\mu \mathrm{L}$ PBS and observed respectively on day 5, day 10 and day 20. D (group 4), E (group 5) and F (group 6) were the treatment groups exposed to Mab bZP3 $(50 \mu \mathrm{L})$ and observed respectively on day 5 , day 10 and day 20 . The BCL-2 expression is indicated by the chromogen brown color in the antral follicle granulosa cells. The observed IRS index of AMH expression of the antral follicle granulosa cells in control groups was stronger than the average score in treatment groups (Immunohistochemistry, $400 \times$ magnification).
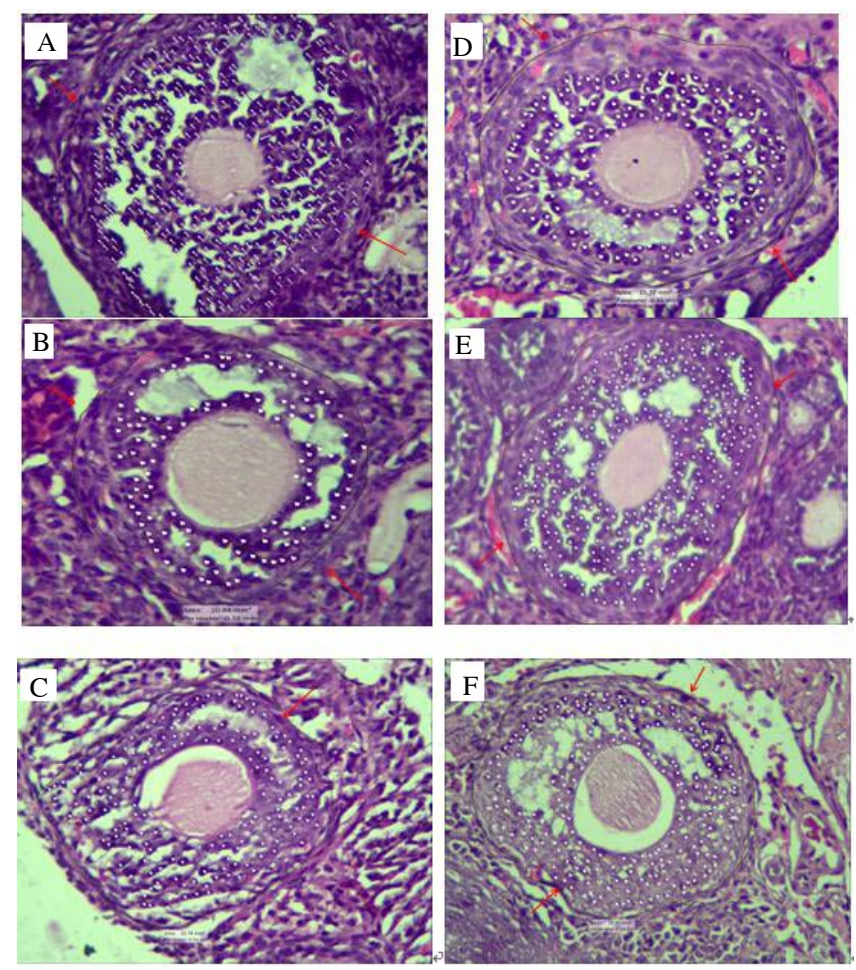

Figure 2. Diameter measurements of mouse antral follicles.

Note: A, B and C were control groups exposed to PBS (50 $\mu \mathrm{L})$ and observed respectively on day 5 , day 10 and day 20 . D, E, F were treatment groups exposed to Mab bZP3 (50 $\mu \mathrm{L})$ and observed respectively on day 5, day 10 and day 20 with $400 \times$ magnification. 


\subsection{Observation of BCL-2 expression}

BCL-2 expression in ovaries was analyzed using a light microscope equipped with a digital camera and image processing software. Data from each sample was observed in five different fields of view (LP) with $400 \times$ and $1000 \times$ magnification. BCL-2 expression in pre-antral follicle granulosa cells and antral follicle was evaluated semiquantitatively using the Remmele method.

Data from each sample assessed semi-quantitatively according to the method that has been modified by Novak et al.[18], where the index scale Remmele (Immuno Reactive Score/IRS) is the multiplication of scores cell percentages immune-reactive to determine the score color intensity on the immuno-reactive cell (Table 1). Data from each sample is the average value of IRS observed in five different visual fields at $400 \times$ and $1000 \times$ magnification. Semi-quantitative scale IRS is the result of multiplying the score percentage of positive cells (A) with a score of intensity of the color reaction $(\mathrm{B})$, so the IRS $=(\mathrm{A} \times \mathrm{B})$.

Table 1

Semiquantitative IRS scale taking into account both percentage of positive cells (A) and intensity of the reaction colour (B), with the final score representing product of the two variables $(\mathrm{A} \times \mathrm{B})$.

\begin{tabular}{ll}
\hline A & B \\
\hline $0 \mathrm{pts}-$ no cells with positive reaction & $0 \mathrm{pts}-$ no colour reaction \\
$1 \mathrm{pt}-$ to $10 \%$ cells with positive reaction $1 \mathrm{pts}-$ low intensity of colour reaction \\
$2 \mathrm{pts}-11-50 \%$ cells with positive reaction & $2 \mathrm{pts}-$ moderate intensity of colour reaction \\
$3 \mathrm{pts}-51-80 \%$ cells with positive reaction & $3 \mathrm{pts}-$ intense colour reaction \\
$4 \mathrm{pts}->80 \%$ cells with positive reaction
\end{tabular}

\subsection{The measurement of follicle diameter}

Follicles were identified after hematoxylin and eosin staining using a light microscope with $400 \times$ magnification equipped with a digital camera and image processing software. The measurements were conducted after the microscope was calibrated to ensure accuracy.

The area of follicles was measured up to the external theca layer using image raster 3 software to determine follicles diameter using following formulae (1). Therefore, to calculate the area of a circle was used to get the radius ( $r$ ) of the follicle using following equation (1).

$$
\mathrm{L}=\pi \times \mathrm{r}^{2} \text { makes } \mathrm{r}=\sqrt{ }(\mathrm{L} / \pi)
$$

The acquired value of $r$ then entered into the formulae to get the diameter of the follicle, as:

$$
\mathrm{L}=\text { Follicle area, } \mathrm{r}=\text { radius }
$$

\section{Results}

\subsection{Analysis of BCL-2 expression}

There was no significant difference in average BCL-2 expression $(P>0.05)$ in the pre-antral follicle and antral on day 5 of observation between the control and treatment groups (Table 2).

On day 10 of observation, there was no significant difference in average BCL-2 expression in the pre-antral follicles between the control and treatment groups $(P>0.05)$ (Table 2). However, there was a significant difference in average BCL-2 expression in the antral follicle $(P<0.05)$. The results of the LSD test showed that the average BCL-2 expression in the treatment groups was lower than that in the control groups.

In addition, there was no significant difference in average BCL-2 expression in the antral and pre-antral follicles on day 20 observations in each control and treatment group $(P>0.05)$ (Table 2$)$.

\subsection{The effect of Mab bZP3 induction on follicle diameter}

The average pre-antral and antral follicle diameters were compared at various observation time. There was no significant difference in average pre-antral and antral follicle diameter on day 5 observation in the control and treatment groups $(P>0.05)$ (Table 3). There was no significant difference in average pre-antral and antral follicle diameters on day 10 observation between control and treatment

Table 2

\begin{tabular}{|c|c|c|c|c|c|c|}
\hline \multirow{2}{*}{ Indexes } & \multicolumn{2}{|c|}{ Day 5} & \multicolumn{2}{|c|}{ Day 10} & \multicolumn{2}{|c|}{ Day 20} \\
\hline & Follicles pre antral & Antral & Follicles pre antral & Antral & Follicles pre antral & Antral \\
\hline Control groups & $6.34 \pm 3.02^{*}$ & $2.55 \pm 0.75^{*}$ & $4.37 \pm 2.83^{*}$ & $2.35 \pm 0.65^{*}$ & $4.37 \pm 2.83^{*}$ & $2.35 \pm 0.65^{*}$ \\
\hline Treatment groups & $3.43 \pm 2.82^{*}$ & $2.10 \pm 0.47^{*}$ & $2.83 \pm 1.92^{*}$ & $1.52 \pm 0.40^{*}$ & $2.83 \pm 1.92^{*}$ & $1.52 \pm 0.40^{*}$ \\
\hline$P$ value & 0.44 & 1.00 & 0.364 & 0.034 & 0.364 & 0.034 \\
\hline
\end{tabular}

Comparison result of average BCL-2 expression on day 5, 10 and 20 obeservation using nested ANOVA.

"Data indicate mean \pm SD.

Table 3

\begin{tabular}{|c|c|c|c|c|c|c|}
\hline \multirow{2}{*}{ Indexes } & \multicolumn{2}{|c|}{ Day 5} & \multicolumn{2}{|c|}{ Day 10} & \multicolumn{2}{|c|}{ Day 20} \\
\hline & Follicles pre antral & Antral & Follicles pre antral & Antral & Follicles pre antral & Antral \\
\hline Control groups & $0.28 \pm 0.05^{*}$ & $4.97 \pm 3.11^{*}$ & $0.26 \pm 0.14^{*}$ & $3.53 \pm 2.97^{*}$ & $0.34 \pm 0.12^{*}$ & $1.63 \pm 2.53$ \\
\hline Treatment groups & $0.34 \pm 0.08^{*}$ & $4.45 \pm 1.01^{*}$ & $0.31 \pm 0.03^{*}$ & $5.39 \pm 1.47^{*}$ & $0.29 \pm 0.05^{*}$ & $2.51 \pm 2.78$ \\
\hline$P$ value & 0.44 & 1.00 & 0.873 & 0.223 & 0.278 & 0.251 \\
\hline
\end{tabular}

Comparison result of average follicle diamter on day 5,10 and 20 obeservation using nested ANOVA.

"Data indicate mean \pm SD. 
groups. On day 20 observation, there was no significant difference in average pre-antral and antral follicle diameters between control and treatment groups $(P>0.05)$ (Table 3$)$.

\section{Discussion}

The immunocontraception induction/allotment at various observation time is required to evaluate its effectivity and safety. The condition for an immunocontraception vaccine is able to provide long-term protection for (6-12) mo. However, the immunocontraception vaccine should not be permanent but should have a specific role during the reproduction process without causing side effects in the reproduction process[1]. In this study, after inducing PBS to the control groups and Mab bZP3 to the treatment group, observations of BCL-2 expression were carried out on day 5 , day 10 and day 20 in accordance with the mouse estrous cycle. To acquire reproduction data, the mice must be operated during the estrous phase[15]. The observation time refers to the human reproduction cycle, which is known as the menstruation cycle with a duration of $\pm 28 \mathrm{~d}$ whereas the estrous cycle lasts for (4-5) d in mice.

Descriptively, this research shows that the average BCL-2 expression in the pre-antral follicles and antral follicles in the treatment groups was lower than that in the other groups at all observation time.

Statistical analysis with nested ANOVA showed no significant difference in average BCL-2 expression between the pre-antral and antral follicles observed on day 5 and day $20(P>0.05)$. This indicated that Mab bZP3 immunization did not interfere with a BCL-2 expression on observation day 5 and 20. Monoclonal antibodies are specific and recognize only one epitope on one antigen, thus, targeting on cell type[12]. The Mab ZP3 will target the ZP3 antigen and affect its function as the identification primary receptor on spermatozoa and interfere with induction of the acrosome reaction. This supports that monoclonal antibodies do not create cross reactions due to their high specificity. The specificity of Mab ZP3 may offer a more effective and safer immunocontraceptive vaccine[13].

The bZP3 post induction could recognize ZP3 as its antigen[14]. The rabbit's serum produced anti-bZP3 antibodies as an immune response to rabbit bZP3. The rabbit anti-bZP3 identified ZP protein as conserved in cows and rabbits, and the binding between antibZP3 and rabbit ZP3 was also observed in oocytes in several follicle developmental phases during the formation of the $\mathrm{ZP}$. Therefore, anti-bZP3 is able to recognize ZP3 as its target during the formation of the oocyte $\mathrm{ZP}$, which is the last primary follicle phase.

Antral follicle BCL-2 expression showed a different pattern on day 10 of observation. There was a significant difference in average BCL-2 expression in the antral follicles between the control and treatment groups $(P<0.05)$. The induction of Mab bZP3 interfered with BCL-2 expression in the antral follicles by day 10 of observation. The decrease in BCL-2 expression indicates an early stage disturbance of granulosa cells. However, this disturbance is temporary because the granulosa cells have a repair mechanism, which was reflected by an increase in BCL-2 expression in antral follicles on observation day 20. Another presumption of the granulosa cell disturbance is due to changes in $\mathrm{ZP}$ structure after the administration of bZP3 monoclonal antibodies. ZP antibodies may affect the function of granulosa cells because part of the ZP is found in the granulosa cell intercellular chamber[7]. The granulosa cells play a major role in reducing the viability of follicles[8], and BCL-2 molecules (prosurvival) are expressed in these granulosa cells[16]. These BCL-2 molecules are important in binding and neutralizing pro-apoptosis proteins that can induce the apoptosis process in granulosa cells. This is consistent with previous results demonstrating that BCL-2 expression is required to support the viability of granulosa cells[8]. Furthermore, a reduction in BCL-2 expression is associated with an increase in follicle atresia[11]. However, the decrease in BCL-2 expression can be affected by other factors, such as homeostasis between BCL-2 family members that are anti-apoptotic. In addition, the BCL-2 expression is also closely related to gonadotropin levels, where the increase in gonadotropin will increase BCL-2 expression and decrease BAX expression. Thus, there are many factors that contribute to BCL-2 expression in granulosa cells, including BAD, BID, and FSH, which were not addressed in this study and are expected to decrease BCL-2 expression.

Follicle diameter can be a sign of follicle viability/survival. Many factors are suspected to influence follicle development that may also affect follicle diameter. The development of ovarian follicles is regulated by different endocrine, paracrine and autocrine signaling mechanisms in their coordination of actions to select the particular follicles for ovulation[8].

The effects of the induction of Mab bZP3 monoclonal antibodies on follicle diameter at different observation time were analyzed in control mice exposed to PBS and in treatment mice exposed to Mab bZP3. One observation time point was selected because the mice required termination. The results were observed once on day 5 for group 1 and 4, on day 10 for group 2 and 5 and on day 20 for group 3 and 6.

The results of day 5 and day 10 showed higher pre-antral follicle diameters in the treatment groups than those in the control groups. However, the pre-antral follicle diameters in the treatment groups were lower than those in the control groups by day 20 . The antral follicle diameters were lower in the treatment groups than in control groups on observation day 5 , in contrast to observation day 10 and day 20 when the antral follicle diameters were higher in the treatment groups than in the control groups. There was no significant difference in average pre-antral and antral follicles diameter on days 5,10 and 20 observation.

Our results showed variable average follicle diameters between the control and treatment groups. The variation in the diameters may 
result from indirect effects of Mab bZP3 induction. The addition of IgG molecules to the ZP will change its structure[9]. It is expected that many follicles undergo atresia due to the disruption of granulosa cells and oocyte growth due to alteration in ZP structure after Mab bZP3 induction. The alterations in ZP structure are proposed to occur due to lysis of the $\mathrm{ZP}$ resulting from the formation of attack complexes on the ZP. The formation of antigen-antibody complexes will activate complement and induce the formation of attack complexes, which will induce the follicular cell apoptotic mechanism and result in follicle atresia[17].

Follicle atresia can be associated with the reductions in BCL-2 expression in the treatment group at all observation time points in this study. BCL-2 is an important molecule to inhibit apoptosis and prevent follicle atresia. Thus, the BCL-2 expression is important to support the development of follicles and suppress cell death[11].

The statistical analysis of our data showed no significant difference in the average diameters of pre-antral and antral follicles at different observation time in each control and treatment group $(P>0.05)$. Therefore, one Mab bZP3 induction does not cause the decrease in follicle diameter at the different observation time suggesting that the induction of Mab bZP3 does not interfere with folliculogenesis as indicated by follicle size. This is the advantage of Mab bZP3 in specifically targeting ZP3-positive cells[14], without disrupting the other major ovarian cells such as the granulosa cells and oocytes. In contrast, rat pre-antral follicles cultured with anti-ZP3 antibodies showed a disruption in the development of follicles and oocytes including reduced follicles diameter size in the treatment groups[10]. The results of this research indicate that Mab bZP3 is a moderately safe immunocontraception candidate. However, further analysis is required to confirm its effectiveness.

These results suggest that Mab bZP3 has the potential to be developed as the safe available immunocontraception materials.

\section{Conflict of interest statement}

The authors declare that they have no conflict of interest.

\section{Acknowledgement}

This acknowlegment is submitted to Prof. Dr. drh Aulanni'am, DES on the donations of monoclonal antibodies bovine zona pelusida 3 (Mab bZP3) so that this research can be undertaken.

\section{References}

[1] Sumitro SB, Soewanto S. Contraception development immunocontraception - basic concepts and research anthology. Surabaya: Airlangga University Press; 2011, p. 15-20.
[2] Gupta SK, Bansa IP, Ganguly A, Bhandari B, Chakrabarti K. Human zona pellusida glycoprotein: Functional relevance during fertilization. $J$ Reprod Immunol 2009; 83(1-2): 50-55.

[3] Sumitro SB, Aulanniam. Women's research innovation immunocontraception molecule based antibody induction results bZP3 and bZP3 DG in basic concepts and research anthology. Surabaya: Airlangga University Press 2011, p. 61-66

[4] Chang RjdE G. Folliculogenesis, ovulation, and luteogenesis in endocrinology. 6th ed. USA: Saunders Elsevier; 2011, p. 2290-2301

[5] Gougeon A. Human ovarian follicular development: From activation of resting follicle to preovulatory maturation. Ann Endocrinol 2010; 71(3): 132-143.

[6] Erickson GF. Follicle growth and development. Global Library Women's Medicine; 2008. doi: 10.3843/GLOWM.10289. [Online]Available from: https://www.glowm.com/section_view/heading/Follicle\%20Growth\%20 and\%20Development/item/288.

[7] Koyama $\mathrm{KdH}$ A. Premature ovarian failure syndrome may be induced by autoimmune reactions to zona pellucida proteins. J Reprod Med Endocrinol 2006; 3(2): 7.

[8] Matsuda F, Naoko I, Manabe N, Ohkura S. Follicular growth and atresia in mammalian ovaries: Regulation by survival and death of granulosa cells. Reprod Develop 2012; 58(1): 44-50.

[9] Barber MR, Fayrer-Hosken RA. Possible mechanisms of mammalian immunocontraception. J Reprod Immunol 2000; 46(2): 103-124.

[10]Colongos G, Hasegawa A, Komori S, Koyama K. Harmful effect of antizona pellusida antibodies in folliculogenesis, oogenesis and fertilization. J Reprod Immunol 2009; 79(2): 148-155.

[11]Ratt VS, Flaws JA, Kolp R, Sorenson CM, Tilly JL. Ablation of BCL-2 gene expression decreases the number of oocytes and prim0rdial follicles established in post natal female mouse gonad. Endocrinology 1995; 136(8): 3665-3668

[12]Putra A, Sumarno, Sundari S. Pertemuan ilmiah bidang imunohistokimia dan western blot. Semarang: Fakultas Kedokteran Universitas Sultan Agung; 2012, p. 57-65

[13]Goldsby R, Kindt TJ, Osborne A. Immunology. California: W.H. Freeman and Company; 2000, p. 63-65.

[14]Widodo EdAa. Specificity of antibody bovine zonna pellucidae 3 (antibZP3) torabbit ZP3 based on bZP3 as contraceptive antigens. Indo $J$ Chem 2005; 5(2): 182-187.

[15]Paixão L, Gaspa-Reis RP, Gonzales G, Santos A, Santana AC, Santos RM, et al. Cigarette smoke impair granulosa cell proliferation and oocyte growth after exposure cessation in young Swiss mice: An experimental study. J Ovarian Res 2012; 5(1): 24.

[16]Nandedkar TD, Dharma SJ. Expression of BCL(xs) and c-myc in atretic follicle of mouse ovary. Reprod Biomed Online 2001; 3(3): 221-225.

[17]Abbas AKdL AH. Celluler and moleculer Immunology. 6th ed. Philadelfia: Saunder an Imprint of Elsivier Inc; 2008, p. 87-106

[18]Novak Mh, Majej JA, Dziegeil. Intensity of ox 2 ekspression in cell of soft tissue fibrosarcomas in dog as related to grade of tumor malignation. But Vet Inst Pulawy 2007; 51(2): 275-279. 